\title{
The association between frequency of eating out with overweight and obesity among children aged 6-17 in China: a National Cross-sectional Study
}

Yanning Ma, Weiyan Gong, Caicui Ding, Chao Song, Fan Yuan, Jing Fan, Ganyu Feng, Zheng Chen and Ailing Liu*

\begin{abstract}
Background: In parallel with the increased prevalence of childhood overweight and obesity, the proportion of eating out in China has increased dramatically in recent years. The purpose of the study was to explore the association between frequency of eating out with overweight and obesity among Chinese children.

Methods: The representative sample was recruited from Chinese National Nutrition and Health Survey (CNNHS) in 2010-2012, which included Chinese children aged 6-17 years (7685 boys and 7576 girls). Frequency of eating out was collected by interview-administered questionnaire and categorized as: 0, 1-2 and $\geq 3$ times per week. Height and weight were measured, consequently body mass index was calculated.

Results: The prevalence of eating out among Chinese children aged 6-17 years old was $23.2 \%$. Children who ate out $0,1-2, \geq 3$ times per week were accounted for $76.8,10.9$ and $12.3 \%$ respectively. Findings revealed that eating out three times per week or more was statistically significant associated with higher prevalence of overweight and obesity among boys (OR $=1.20,95 \mathrm{Cl}: 1.04-1.38)$ compared with those ate out less than three times per week. However, no significantly association was observed among girls ( $\mathrm{OR}=0.91,95 \mathrm{Cl}: 0.78-1.01)$. In additional, Younger children, rural children, children from low income family, those with leisure exercises (certain physical activities regularly carried out such as swimming, walking, running, equipment fitness), leisure time sedentary behaviors $($ LTSB) $(>2 \mathrm{~h} / \mathrm{d})$ were relatively more likely to eat out.
\end{abstract}

Conclusions: The results illustrated that eating out three times or more had a significantly positive effect on overweight and obesity among boys in China.

Keywords: China, Eating out, Frequency, Overweight and obesity, Children

\section{Background}

The worldwide prevalence of overweight and obesity among children has becoming a global health problem $[1,2]$. The prevalence of overweight and obesity among

\footnotetext{
* Correspondence: liual@ninh.chinacdc.cn

Department of Nutrition and Health Education, National Institute for Nutrition and Health, Chinese Center for Disease Control and Prevention, No. 27 Nanwei Road, Xicheng District, Beijing 100050, China
}

children has increased by $47.1 \%$ globally between 1980 and 2013 [3]. Increases were observed in both developed countries and developing societies [4]. The number of childhood overweight and obesity also increased dramatically over the past decades in China [5]. A recently report among Chinese students aged 7-18 years old showed that the nationwide prevalence of overweight and obesity increased from 2.1 to $12.2 \%$, 0.5 to $7.3 \%$ from

(c) The Author(s). 2021 Open Access This article is licensed under a Creative Commons Attribution 4.0 International License, which permits use, sharing, adaptation, distribution and reproduction in any medium or format, as long as you give appropriate credit to the original author(s) and the source, provide a link to the Creative Commons licence, and indicate if changes were made. The images or other third party material in this article are included in the article's Creative Commons licence, unless indicated otherwise in a credit line to the material. If material is not included in the article's Creative Commons licence and your intended use is not permitted by statutory regulation or exceeds the permitted use, you will need to obtain permission directly from the copyright holder. To view a copy of this licence, visit http://creativecommons.org/licenses/by/4.0/ The Creative Commons Public Domain Dedication waiver (http://creativecommons.org/publicdomain/zero/1.0/) applies to the data made available in this article, unless otherwise stated in a credit line to the data. 
1985 to 2014, respectively, and this proportion was expected to reach $28 \%$ or affected 3496 million children by 2030 [6]. The previous studies suggested that overweight and obesity children had an risk of adult obesity [7], which will result to an increased morbidity and mortality $[8,9]$. Childhood overweight and obesity correlate with high blood pressure, heart disease and other chronic disease [10]. Childhood overweight and obesity is attributed to complex interaction of genetic, environmental and other behavior factors $[11,12]$.

In parallel with rapid economic development, the dietary structure and eating behaviors have undergone great changes [13, 14], eating out has become a continuously growing part of the Chinese dietary pattern. According to the statistics released by China's National Bureau of Statistics,carting revenue increased from 74.03 billion RMB in 2002 to 441.99 billion RMB in 2012, which raised almost 5 times [15]. In terms of eating out associate with higher intake of total energy, total fat, sodium, and sugar and lower intakes of fiber, vitamins, and minerals $[16,17]$,the available data have suggested that eating at restaurant may increase the consumption of meat, sweet while reducing the intake of grains, vegetables and fruits [13]. Furthermore, a large numbers of literature have indicated that eating out was associated with higher intake of energy [13, 16-18], the increasing energy intake from restaurant drove overall increase in daily energy [19]. thus it may contribute to energy unbalanced that cause weight gain [16]. As number of eating out occasion continues to increase, more attention are paid to the relationship between eating out with overweight and obesity.

Aristides [20] et al. demonstrated that children who ate at restaurant had a $21 \%$ higher risk of being overweight than those who did not eat at restaurant. Many abroad studies were conducted by nationally representative or large cohort data from west countries. A research [21] of 3-12 years children in 9 areas of China found the positive relationship between eating out and risk of overweight and obesity or BMI, mainly due to the substantial contribute of eating out to increase the energy intake [22]. A study [23] of Guangzhou middle school students reported that those consuming restaurant food once a week or more was associated with a $38 \%$ higher prevalence, compared with those who never ate at restaurant after adjusting for age, single child family structure, household income, and culture of students' parents. However, available data on the association between eating out and overweight and obesity among Chinese children are far from conclusive. Besides the data of previous published was not representative of the national children population. The objective of the current study was to examine the association between frequency of eating out with overweight and obesity in a nationally representative sample of children using the data of Chinese Nutrition and Health Surveillance (CNNHS) in 2010-2012, then to provide basic information to aid in developing eating out intervention strategies.

\section{Method \\ Study participants}

Data used in this study were from the Chinese Nutrition and Health Surveillance (CNNHS) from 2010 to 2012. The nationally representative cross-sectional study was implemented by the National Institute for Nutrition and Health, Chinese Center for Disease Control and Prevention (NINH, China $\mathrm{CDC}$ ) to assess the the nutritional status of Chinese residents. The survey covered 31 provinces, autonomous regions and municipalities (except Taiwan, Hong Kong and Macao) from 2010 to 2012. The method of multi-stage stratification and population proportional cluster random sampling was adopted. In accordance with economic development, all county-level administrative units were divided into four categories: big cities, small and medium-sized cities, ordinary rural areas and poor rural areas. A total of 150 counties (districts) were selected from four categories of areas as study sites, including 34 big cities, 41small and mediumsized cities, 45 ordinary rural areas and 30 poor rural areas, respectively. The study selected 25 households randomly from each village/community and children aged 6 to 17 years in each family were involved. If the number of children in each age group in each location is less than 20 (10 boys and 10 girls), supplementary children would be selected from nearby primary and secondary schools to reach the minimum sample size. The specific sampling method can be referred in the published literature [24]. After eliminated missing and abnormal data in height, weight, frequency of eating out and sedentary time, a total of 15,261 participants (7685 boys, 7576 girls) aged 6 to 17 years were recruited.

The informed consent was approved by the ethics review committee of the National Institute for Nutrition and Food Safety, Chinese Center for Disease Control and Prevention (No. 2013-018). All participants' parents or legal guardian were fully informed the purpose and signed the informed consent.

\section{Data collection}

The interview-administered questionnaire was used to collect the information of basic socio-economics, sedentary duration and leisure exercise. The food frequency questionnaire (FFQ) was used to collect eating behaviors over the past week. The details of food frequency questionnaire were attached in additional file 1 . Respondents were asked "How many times have you had breakfast, lunch, or dinner in the past week (seven days)?" and "How many times in the past week have you had breakfast, lunch, or dinner at a restaurant or school canteen?". 
All the questionnaires were collected by trained investigator by face-to-face interview, and the interviews were conducted at the homes of the participants. The children younger than 12 years old finished the questionnaire with the help of their parents or legal guardian. To ensure the reliability of data, quality control measures and evaluation indexes were made at the national, provincial and district levels, quality control was carried out in the period of field survey.

\section{Categories of frequency of eating out}

In the current study, eating out was defined as eating a meal or more prepared by restaurants. Frequency of eating out was categorized as three levels: 0 time, 1-2 times, or 3 times and over per week.

\section{Anthropometric measurements}

The height was measured with an accuracy of $0.1 \mathrm{~cm}$ and the fasting weight was measured with an accuracy of $0.1 \mathrm{~kg}$. All measurements were conducted by welltrained investigators under standard operation procedure. Body mass index (BMI) was calculated as a division of weight in kilograms by the square of height in meters.

\section{Definition of weight status}

Overweight and obesity was classified based on age- and gender-specific BMI cutoff points among Chinese children [25]. In the meantime, national health standard of Screening standard for malnutrition of school-age children and adolescents was devoted to screen for underweight children [26].

\section{Assessment of sociodemographic determinants}

Age groups were divided into two categories (6-12, 1317 years). Participants were divided into four residency groups according to location (urban, suburban, rural and poor rural). Family income was classified into four levels (<20,000 RMB/person, 20,000-40,000 RMB/person, > 40,000 RMB/person, and unkown). Leisure exercise was defined as two levels (No/Yes). Sedentary duration status was grouped into two levels $(\leq 2 \mathrm{~h} / \mathrm{d}$ and $>2 \mathrm{~h} / \mathrm{d}$ ).

\section{Statistical analysis}

All statistical analyses were conducted using SPSS 22.0. The univariate descriptive statistics were conducted for each variable (frequency and percentage), and the frequency of eating out was expressed as a percentage. Data were run to compare means between different gender, age,leisure exercise and leisure SB groups using $t$ tests, data were run to compare means of region, family-income and BMI status using Chisquare tests. Multivariate logistic regression analysis was used to analyze the relationship between eating out and overweight and obesity. After adjusting for age, region, logistic regression was employed to examine the association of eating out with overweight and obesity, where dependent variable was BMI status (obesity, overweight, normal weight and underweight), and adjusted odds ratios (OR) with 95\% confidence intervals (CI) were obtained. Statistical significance was considered at $p<0.05$.

\section{Result}

The distribution of the characteristics among participants The characteristics of Chinese children aged 6-17 years are presented in Table 1. In this study, the number of children involved in the survey was 15 , 261, 7685 boys and 7575 girls were included, and the number of urban, suburban, rural and poor rural residents was 26.1, 27.3, 33.1 and $13.5 \%$, respectively. Children of 6-12 and 13-17 years accounted for 61.8 and $31.2 \%$. Children from different family incomes accounted for $60.0,15.4,4.4$ and $20.2 \%$ respectively. The detailed distribution of leisure exercise, family

Table 1 Demographic characteristics of participant

\begin{tabular}{|c|c|c|c|c|c|c|}
\hline Variables & $\begin{array}{l}\text { Boys } \\
\mathrm{N}\end{array}$ & $\begin{array}{l}\% \text { of } \\
\text { Sub- } \\
\text { Group }\end{array}$ & $\begin{array}{l}\text { Girls } \\
\mathrm{N}\end{array}$ & $\begin{array}{l}\% \text { of } \\
\text { Sub- } \\
\text { Group }\end{array}$ & $\begin{array}{l}\text { All } \\
\mathrm{N}\end{array}$ & $\begin{array}{l}\% \text { of } \\
\text { Sub- } \\
\text { Group }\end{array}$ \\
\hline \multicolumn{7}{|l|}{ Age (years) } \\
\hline $36-12$ & 4724 & 61.5 & 4712 & 62.2 & 9436 & 61.8 \\
\hline $13-17$ & 2961 & 38.5 & 2864 & 37.8 & 5825 & 38.2 \\
\hline \multicolumn{7}{|l|}{ Region } \\
\hline Urban & 1992 & 25.9 & 1995 & 26.3 & 3987 & 26.1 \\
\hline Suburban & 2093 & 27.2 & 2071 & 27.3 & 4164 & 27.3 \\
\hline Rural & 2566 & 33.4 & 2487 & 32.8 & 5053 & 33.1 \\
\hline Poor rural & 1034 & 13.5 & 1023 & 13.5 & 2057 & 13.5 \\
\hline \multicolumn{7}{|l|}{ Family income } \\
\hline Low & 4628 & 60.2 & 4528 & 59.8 & 9156 & 60.0 \\
\hline Medium & 1195 & 15.5 & 1153 & 15.2 & 2348 & 15.4 \\
\hline High & 360 & 4.7 & 312 & 4.1 & 672 & 4.4 \\
\hline Unknown & 1502 & 19.5 & 1583 & 20.9 & 3085 & 20.2 \\
\hline \multicolumn{7}{|l|}{ Leisure exercise } \\
\hline No & 4294 & 55.9 & 4537 & 59.9 & 8831 & 57.9 \\
\hline Yes & 3391 & 44.1 & 3039 & 40.1 & 6430 & 42.1 \\
\hline \multicolumn{7}{|l|}{ Leisure SB } \\
\hline$\leqq 2 \mathrm{~h} / \mathrm{d}$ & 2952 & 38.4 & 2928 & 38.6 & 5880 & 38.5 \\
\hline$>2 \mathrm{~h} / \mathrm{d}$ & 4733 & 61.6 & 4648 & 61.4 & 9381 & 61.5 \\
\hline \multicolumn{7}{|l|}{ BMI status } \\
\hline Obesity & 991 & 12.9 & 631 & 8.3 & 1622 & 10.6 \\
\hline Overweight & 1140 & 14.8 & 875 & 11.5 & 2015 & 13.2 \\
\hline Normal & 5024 & 65.4 & 5668 & 74.8 & 10,692 & 70.1 \\
\hline Underweight & 530 & 6.9 & 402 & 5.3 & 932 & 6.1 \\
\hline
\end{tabular}


income, leisure SB and weight status among different genders are shown in Table 1.

\section{The frequency of eating outside of participants}

The characteristics of participants were presented in Table 2. Children who ate out $0,1-2$ and $\geq 3$ times per week were accounted for $76.8,10.9$ and $12.3 \%$, respectively. Although no significant gender difference in frequency of eating out was observed, we found that there was a trend that children from economic developed region and low income family eat out more often $(P<0.05)$. Compared with their counterparts, younger children, those with leisure exercise, leisure SB $(>2 \mathrm{~h} / \mathrm{d})$ were more likely to eat out $(P<0.05)$. In additional, Table 1 shows the frequency distribution of eating out is significantly different among children with different weight status $(P<0.05)$.

\section{Logistic regression analysis of the relationship between frequency of eating out with overweight and obesity} The relationship between frequency of eating out with overweight and obesity were presented in Table 3. In model 1 , eating out was positively and significantly associated with overweight and obesity among children $(\mathrm{OR}=1.18,95 \%$ CI: 1.04-1.34), No significant relationship was observed among girls (OR $=0.97,95$ CI: $0.83-$ 1.21). After further adjustment for leisure exercises and leisure time sedentary behaviors, the estimates of the

Table 2 The frequency of eating outside of participants

\begin{tabular}{|c|c|c|c|c|c|c|}
\hline \multirow[t]{3}{*}{ Variables } & \multirow{3}{*}{$\begin{array}{l}\text { Total } \\
\mathrm{N}\end{array}$} & \multicolumn{3}{|c|}{ Eating-out (times/ week) } & \multirow[t]{3}{*}{$x^{2}$} & \multirow[t]{3}{*}{$P$} \\
\hline & & 0 & $1-2$ & $\geq 3$ & & \\
\hline & & $\mathrm{N}(\%)$ & $\mathrm{N}(\%)$ & $N(\%)$ & & \\
\hline Total & 15,261 & $11,724(76.8)$ & $1668(10.9)$ & $1869(12.3)$ & & \\
\hline Gender & & & & & 3.47 & 0.177 \\
\hline Boys & 7685 & $5887(50.2)$ & $822(49.3)$ & $976(52.2)$ & & \\
\hline Girls & 7576 & $5837(49.8)$ & $846(50.7)$ & $893(47.8)$ & & \\
\hline Age (years) & & & & & 98.52 & $<0.001$ \\
\hline $6-12$ & 9436 & $7491(63.9)$ & $956(57.3)$ & 989 (52.9) & & \\
\hline $13-17$ & 5825 & $4233(36.1)$ & $712(42.7)$ & $880(47.1)$ & & \\
\hline Region & & & & & 1127.52 & $<0.001$ \\
\hline Urban & 3987 & $2455(20.9)$ & $696(41.7)$ & $838(44.7)$ & & \\
\hline Suburban & 4164 & $2996(25.6)$ & $551(33.0)$ & $617(33.0)$ & & \\
\hline Rural & 5053 & $4455(38.0)$ & $253(15.2)$ & $345(18.5)$ & & \\
\hline Poor rural & 2057 & $1818(15.5)$ & $168(10.1)$ & $71(3.8)$ & & \\
\hline Family income & & & & & 362.46 & $<0.001$ \\
\hline Low & 9156 & 7469 (63.7) & $773(46.4)$ & $914(48.9)$ & & \\
\hline Medium & 2348 & $1645(14.0)$ & $331(19.8)$ & $372(19.9)$ & & \\
\hline High & 672 & $386(3.3)$ & $147(8.8)$ & $139(7.4)$ & & \\
\hline Unknown & 3085 & 2224 (19.0) & $417(25.0)$ & $444(23.8)$ & & \\
\hline Leisure exercise & & & & & 285.49 & $<0.001$ \\
\hline No & 8831 & 7219 (61.6) & 767 (46.0) & $845(45.2)$ & & \\
\hline Yes & 6430 & 4505 (38.4) & $901(54.0)$ & $1024(54.8)$ & & \\
\hline Leisure SB & & & & & 150.01 & $<0.001$ \\
\hline$\leq 2 \mathrm{~h} / \mathrm{d}$ & 5880 & $4824(41.2)$ & $526(31.5)$ & $530(28.4)$ & & \\
\hline$>2 \mathrm{~h} / \mathrm{d}$ & 9381 & 6900 (58.8) & $1142(68.5)$ & 1339 (71.6) & & \\
\hline BMI status & & & & & 35.34 & $<0.001$ \\
\hline Obesity & 1622 & $1212(10.3)$ & 189 (11.3) & 221 (11.8) & & \\
\hline Overweight & 2015 & 1499 (12.8) & $231(13.9)$ & $285(15.3)$ & & \\
\hline Normal & 10,692 & $8238(70.3)$ & $1181(70.8)$ & $1273(68.1)$ & & \\
\hline Underweight & 932 & 775 (6.6) & $67(4.0)$ & $90(4.8)$ & & \\
\hline
\end{tabular}


Table $\mathbf{3}$ Logistic regression analysis of frequency of eating out and overweight and obesity.

\begin{tabular}{|c|c|c|c|c|c|c|c|}
\hline \multirow[t]{2}{*}{ Model } & \multirow{2}{*}{$\begin{array}{l}\text { Eating out } \\
\text { times/ week }\end{array}$} & \multicolumn{2}{|l|}{ Total } & \multicolumn{2}{|l|}{ Boys } & \multicolumn{2}{|l|}{ Girls } \\
\hline & & OR(95\%Cl) & $P$ & OR(95\%Cl) & $P$ & $\mathrm{OR}(95 \% \mathrm{Cl})$ & $P$ \\
\hline \multicolumn{8}{|c|}{ Model $1^{a}$} \\
\hline & 0 & Reference & & & & & \\
\hline & $1-2$ & $1.18(1.04-1.34)$ & 0.009 & $1.37(1.17-1.62)$ & $<0.001$ & $0.97(0.80-1.18)$ & 0.757 \\
\hline & $\geq 3$ & $1.22(1.09-1.37)$ & 0.001 & $1.37(1.18-1.60)$ & $<0.001$ & $1.00(0.83-1.21)$ & 0.992 \\
\hline \multicolumn{8}{|c|}{ Model $2^{b}$} \\
\hline & 0 & Reference & & & & & \\
\hline & $1-2$ & $1.13(1.00-1.28)$ & 0.054 & $1.32(1.12-1.56)$ & $<0.001$ & $0.93(0.76-1.13)$ & 0.471 \\
\hline & $\geq 3$ & $1.16(1.03-1.31)$ & 0.012 & $1.31(1.13-1.53)$ & $<0.001$ & $0.96(0.79-1.16)$ & 0.673 \\
\hline \multicolumn{8}{|c|}{ Model $3^{c}$} \\
\hline & 0 & Reference & & & & & \\
\hline & $1-2$ & $1.04(0.92-1.18)$ & 0.522 & $1.15(0.97-1.37)$ & 0.099 & $0.91(0.74-1.11)$ & 0.346 \\
\hline & $\geq 3$ & $1.09(0.96-1.23)$ & 0.178 & $1.21(1.03-1.41)$ & 0.020 & $0.92(0.76-1.13)$ & 0.432 \\
\hline
\end{tabular}

a. model1: The model analyzed the frequency of eating out and overweight and obesity.

b. Model 2: The model adjusted leisure exercises and leisure time sedentary behaviors upon model 1.

c. Model 3: Additional adjusted for age, region, family income upon model 2.

association was reduced, but the significance of the association remained (model 2). Additional adjustment for age, gender, region, family income,, those who ate out 3 times or more per week had a higher risk of overweight and obesity $(\mathrm{OR}=1.21,95 \% \mathrm{CI}: 1.03-1.41)$ in boys group, compared to those who ate out less than 3 times a week. No significant relationship was observed among girls $(\mathrm{OR}=0.91,95 \mathrm{CI}: 0.78-1.01)$.

\section{Discussion}

In peace the rapid rapid economic development, the dietary structure and lifestyle have changed greatly. The study found that more than half of children ate out, which was higher than the national average of $28.3 \%$ as reported by the China National Health and Nutrition Survey in 2002. In parallel with an increase in the prevalence of overweight and obesity among children, the rate of eating out has increased rapidly in recent years. The current study clearly demonstrated the significant association between overweight and obesity with higher frequency of eating outside among boys, similar results were observed in previous researches: as in Brazilian children [27], and had been found among children from Etiology of Childhood Obesity (ECHO) study [28], among children and adolescents aged 11-14 years in London Borough [29], in Portugal children [20] and in US elementary schools students [30]. However, we did not observe a significant association between obesity and eating out in group of girls, which may due to boys' greater preference for fatty food and girls pay more attention to their weight [31-33]. Whereas, the result of the UK National Diet and Nutrition Survey (NDNS) indicated that no association between energy intake and frequency of consumption of meals out in children [34]. The difference of the research results probable partly due to the lack of a unified standard for the definition of dining out. The definition for our research was refer to restaurant only, the scope is relatively limited. Moreover, at present, our research data are mainly from the results of the 2010-2012 survey, With the rapid development of catering industry in recent years. Furthermore, our research data are mainly from the finding of investigation in 2010-2012, in peace with the rapid expansion of the catering industry in recent years, consuming food from restaurant has became more convenience. Children have easy access to eat out or order online, which probably lead the increasing frequency of eating out among children. Therefore, it is necessary to take corresponding strategies and interventions to to prevent unhealthy eating behaviors among children, such as diversified health and nutrition education should be applied among children and parents.

Consistent with previous studies [18, 35], 6-12 years children were more likely to be overweight and obesity compared with 13-17 years children, which may be related to the fact that younger children tended to eat out. One possible explanation from previous research [36, 37] suggested that older children tend to choose more healthy food, which may related to the growing conception of healthy eating behavior among older children. Thus, more researches are needed to provide dietary guidance of eating out on younger children. Additionally, the study found that children from high-income household were associated with greater prevalence of 
overweight and obesity, the finding supported by previous researches [38, 39]. Li Miao found that children from high income family with more pocket money tend to be overweight and obesity [40]. however, opposite to previous research [31] lower rate of frequency of eating out was found among children from high-income family, which may be related to the fact that the rate of overweight and obesity was higher among children from high-income family, then they were less likely to eat out. Furthermore, The study showed that in comparison with children in rural regions, children from urban regions tended to be overweight and obesity, and this difference was also found in other domestic studies [41, 42], which was likely due to the convenience of eating out in the urban regions [43]. Similar result was founded in a survey conducted among Mexican children found that urban children [44] consumed more energy daily than those in the rural regions. Therefore, dietary nutrition education and intervention about healthy eating is necessary. As seen in the current study, children who do leisure exercise tended to eat out, It could be because of the energy expenditure caused by doing exercise, which leads children tend to foods sold in restaurants with better flavor color and taste. Leisure exercise was positive associated with high rate of overweight and obesity, which may be related to the fact that majority of childhood obesity prevention program implemented among obese rather than non-obese children [45], thus Obese children were more likely to participate in exercises [46]. We also found that children those had more leisure sedentary time tended to eat out. The similar result was found among Pakistan children aged 5 to 12 years showed that eating fast food had a significant association with sedentary behavior [47] and Matheson's study [48]. Sedentary which included watching television and playing video game, television advertising of restaurant foods were attractive for children, which was the possible explanation of the higher rate of eating out. Preventive strategies and practical approaches may need to reduce children's sedentary time.

The main advantages of this study were that the sample was nationally representative, which can reflect the nutrition and health status of Chinese children. The data gave a general description of eating out behavior of Chinese children aged 6-17 years, and the result provided a reference for further research with similar situation. Additionally, as eating out has become an integral part of the daily life, many researches of relationship between eating out and dietary quality among children, while, insufficient guidance of the maximum recommended frequency of eating out were existed. The result of this study provide reference times for eating out by genders. However, the current study had several limitations. Firstly, as the definition of eating out which including restaurant only. Which may underestimate the frequency of eating out; secondly, this study was crosssectional study, the causal relationship between the eating out and overweight and obesity cannot be determined; finally, The calculated intake of energy and other nutrients is deficient, only the frequency of eating out in the interview-administered questionnaire table are analyzed. Therefore, the conclusion of the study still has practical significance.

\section{Conclusion}

In conclusion, the result of this study demonstrated that the prevalence of eating out was $23.3 \%$ among Chinese children. Younger children, urban children and children from low-income family were more likely to eat out. Thus, dietary nutritional education and intervention about healthy eating is necessary. Considering the higher risk overweight and obesity among boys, interventions regarding eating out should tailor messages appropriately to target specific subjects by genders. From a public health perspective, the result suggested that interventions are needed to strengthen the monitoring of the situation of children eating out, thus contributing to reduce the potential enormous economic costs that are associated with eating out behavior-related illnesses, such as overweight and obesity.

\section{Abbreviations \\ CNNHS: Chinese national nutrition and health survey; WHO: World health organization; NINH, China CDC: National institute for nutritionand health, chinese center for disease control and prevention; 95\% Cls: Confidence intervals; ECHO: Etiology of childhood obesity; NDNS: UK national diet and nutrition survey; LTSB: Leisure time sedentary behaviors}

\section{Supplementary Information}

The online version contains supplementary material available at https://doi. org/10.1186/s12889-021-11104-0.

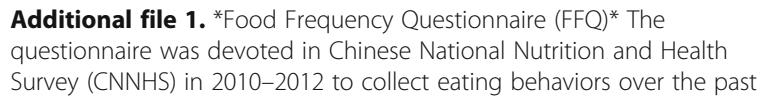

\section{Acknowledgments}

We thank all team members and participants for the China National and Health Survey (CHNHS 2010-2012).

\section{Authors' contributions}

The authors' contributions were as follows: Y.M. participated in the data clean, data check and analysis, wrote the manuscript. A.L. designed the study and revised the manuscript. W.G., C.D., C. S, F.Y., J.F.,G.F. and Z.C. collected and supervised the data. All authors read and approved the final manuscript.

\section{Funding}

The 2010-2012 CNNHS was supported by Medical Reform Major Program from the National Health and Family Planning Commission of the People's Republic of China (No.20120212). Subsequently established working group to organize and carry out the investigation plan of the survey . 


\section{Availability of data and materials}

The data sets generated and/or analyzed during the current study are not publicly available as some results are still being analyzed but are available from the corresponding author on reasonable request.

\section{Declarations}

\section{Ethics approval and consent to participate}

The informed consent of the 2010-2012 CNNHS was approved by the Ethical Committee of National Institute for Nutrition and Health (NINH), Chinese Center for Disease Control and Prevention (2013-018). Our study was approved by the Ethical Committee of NINH. We have received administrative permission to access the data from National Institute for Nutrition and Health (NINH), Chinese Center for Disease Control and Prevention.

\section{Consent for publication}

Not applicable.

\section{Competing interests}

The authors declare that they have no competing interests.

Received: 19 July 2020 Accepted: 19 May 2021

Published online: 28 May 2021

\section{References}

1. World Health Organisation. Childhood overweight and obesity report. Report of a WHO consultation. In: WHO technical report series, no. 894. Geneva: World Health Organisation; 2015. http://www.who.int/dietphysicala ctivity/childhood/en/.

2. Sabin MA, Kao KT, Juonala M, Baur LA, Wake M. Viewpoint article: childhood obesity--looking back over 50 years to begin to look forward. J Paediatr Child Health. 2015;51(1):82-6. https://doi.org/10.1111/jpc.12819.

3. Ng M, Fleming T, Robinson M, Thomson B, Graetz N, Margono C, et al. Global, regional, and national prevalence of overweight and obesity in children and adults during 1980-2013: a systematic analysis for the global burden of disease study 2013. Lancet (London, England). 2014;384(9945): $766-81$

4. Gupta N, Shah P, Nayyar S, Misra A. Childhood obesity and the metabolic syndrome in developing countries. Indian J Pediatr. 2013;80(Suppl 1):S28-37.

5. Sun $\mathrm{H}, \mathrm{Ma}$ Y, Han D, Pan CW, Xu Y. Prevalence and trends in obesity among China's children and adolescents, 1985-2010. PLoS One. 2014;9(8):e105469. https://doi.org/10.1371/journal.pone.0105469.

6. Ma G, Jie M. Report on childhood obesity in China, vol. 12. Beijing, China: People's Health Publishing House; 2017.

7. Huang JY, Qi SJ. Childhood obesity and food intake. World J Pediatr. 2015: 11(2):101-7. https://doi.org/10.1007/s12519-015-0018-2.

8. Simmonds $\mathrm{M}$, Burch J, Llewellyn A, Griffiths $\mathrm{C}$, Yang $\mathrm{H}$, Owen $\mathrm{C}$, et al. The use of measures of obesity in childhood for predicting obesity and the development of obesity-related diseases in adulthood: A systematic review and meta-analysis. Health Technol Assess. 2015;19:1-336.

9. Xu S, Xue Y. Pediatric obesity: causes, symptoms, prevention and treatment. Exp Ther Med. 2016;11(1):15-20. https://doi.org/10.3892/etm.2015.2853.

10. Piernas C, Wang D, Du S, Zhang B, Wang Z, Su C, et al. Obesity, noncommunicable disease (NCD) risk factors and dietary factors among Chinese school-aged children. Asia Pac J Clin Nutr. 2016;25(4):826-40. https://doi. org/10.6133/apjcn.092015.37.

11. Silventoinen K, Rokholm B, Kaprio J, Sørensen TI. The genetic and environmental influences on childhood obesity: a systematic review of twin and adoption studies. Int J Obes (Lond). 2010;34(1):29-40.

12. Janssen I, Katzmarzyk PT, Boyce WF, Vereecken C, Mulvihill C, Roberts C, et al. Comparison of overweight and obesity prevalence in school-aged youth from 34 countries and their relationships with physical activity and dietary patterns. Obes Rev. 2005;6(2):123-32. https://doi.org/10.1111/j.1467789X.2005.00176.x.

13. Seguin RA, Aggarwal A, Vermeylen F, Drewnowski A. Consumption frequency of foods away from home linked with higher body mass index and lower fruit and vegetable intake among adults: a cross-sectional study. J Environ Public Health. 2016;2016:3074241.
14. Bezerra IN, Curioni C, Sichieri R. Association between eating out of home and body weight. Nutr Rev. 2012;70(2):65-79. https://doi.org/10.1111/j.1 753-4887.2011.00459.x

15. National Bureau of Statistics. China Statistical Yearbook. Beijing, China: China Statistics Press; 2012.

16. Jaworowska A, Blackham T, Long R, Taylor C, Ashton M, Stevenson L, et al. Nutritional composition of takeaway food in the UK. Nutr Food Sci. 2014; 44(5):414-30. https://doi.org/10.1108/NFS-08-2013-0093.

17. Powell LM, Nguyen BT. Fast-food and full-service restaurant consumption among children and adolescents: effect on energy, beverage, and nutrient intake. JAMA Pediatr. 2013;167(1):14-20. https://doi.org/10.1001/jamapedia trics.2013.417.

18. Larson N, Neumark-Sztainer D, Laska MN, Story M. Young adults and eating away from home: associations with dietary intake patterns and weight status differ by choice of restaurant. J Am Diet Assoc. 2011;111(11):1696703. https://doi.org/10.1016/j.jada.2011.08.007.

19. Lachat C, Nago E, Verstraeten R, Roberfroid D, Van Camp J, Kolsteren P. Eating out of home and its association with dietary intake: a systematic review of the evidence. Obes Rev. 2012;13(4):329-46. https://doi.org/1 0.1111/j.1467-789X.2011.00953.x.

20. Machado-Rodrigues AM, Gama A, Mourão I, Nogueira H, Rosado-Marques V, Padez C. Eating away from home: a risk factor for overweight in children. Eur J Clin Nutr. 2018;72(12):1724-7. https://doi.org/10.1038/s41430-018-0165-3.

21. Zhang Y, Wang J, Xue Y, Zheng Y, Wang P, Zhang Y. Investigation on relevant factors of eating out and fast food and overweight and obesity among 3-12 years old children in 9 areas of China. Zhong Guo Fu You Bao Jian Matern Child Health Care China. 2014;31:5132-5.

22. Giovanna CA, Maria FG, Maria L, Catarina MA, Renata BL. The consumption of ultra-processed foods according to eating out occasions. Public Health Nutr. 2020;236(3):1041-8.

23. Deng J, Yang S, Ao L, Li B, Zou Z, Li L, et al. Influencing factors of family eating out and its correlation withoverweight and obesity among urban fresh middle school students in Guangzhou City. Xian Dai Yi Yao Wei Sheng J Modern Med Health. 2019;35(10):1455-9.

24. Zhao L, Ma G, Piao J, Zhang J, Yu D, He Y, et al. Scheme of the 2010-2012 Chinese nutrition and health surveillance. Zhong Hua Yu Fang Yi Xue Za Zhi. 2016;50(3):204-7.

25. Group of China Obesity Task Force Correspondence. Body mass index reference norm for screening overweight and obesity in Chinese children and adolescents. Zhonghua Liu Xing Bing Xue Za Zhi Chin J Epidemiol. 2004;25(2):97-102.

26. Dong YH, Wang ZH, Yang ZG, Wang XJ, Chen YJ, Zou ZY, et al. Epidemic status and secular trends of malnutrition among children and adolescents aged 7-18 years from 2005 To 2014 in China. Beijing Da Xue Xue Bao. 2017; 49(3):424-32.

27. Bezerra IN, de Moura SA, Pereira RA, Sichieri R. Contribution of foods consumed away from home to energy intake in Brazilian urban areas: the 2008-9 Nationwide dietary survey. Br J Nutr. 2013;109(7):1276-83. https:// doi.org/10.1017/S0007114512003169.

28. Fulkerson JA, Farbakhsh K, Lytle L, Hearst MO, Dengel DR, Pasch KE, et al. Away-from-home family dinner sources and associations with weight status, body composition, and related biomarkers of chronic disease among adolescents and their parents. J Am Diet Assoc. 2011;111(12):1892-7. https://doi.org/10.1016/j.jada.2011.09.035.

29. Patterson R, Risby A, Chan MY. Consumption of takeaway and fast food in a deprived inner London Borough: are they associated with childhood obesity? BMJ Open. 2012;2:e000402. https://doi.org/10.1136/bmjopen-2011000402.

30. Ayala GX, Rogers M, Arredondo EM, Campbell NR, Baquero B, Duerksen SC, et al. Away-from-home food intake and risk for obesity: examining the influence of context. Obesity (Silver Spring). 2008;16(5):1002-8.

31. Qiu C, Hou M. Association between food preferences, eating behaviors and socio-demographic factors, physical activity among children and adolescents: a cross-sectional study. Nutrients. 2020;12(3):640.

32. Kimura S, Endo Y, Minamimae K, Kanzaki S, Hanaki K. Gender differences in childhood food preference: evaluation using a subjective picture choice method. Pediatr Int. 2014;56(3):389-94. https://doi.org/10.1111/ped.12276.

33. Cooke $L$, Wardle J. Age and gender differences in children's food preferences. Br J Nutr. 2005;93(5):741-6. https://doi.org/10.1079/BJN20051389.

34. Goffe L, Rushton S, White M, Adamson A, Adams J. Relationship between mean daily energy intake and frequency of consumption of out-of-home 
meals in the UK National Diet and nutrition survey. Int J Behav Nutr Phys Act. 2017;14(1):131. https://doi.org/10.1186/s12966-017-0589-5.

35. Adams J, Goffe L, Brown T, Lake AA, Summerbell C, White M, et al. Frequency and socio-demographic correlates of eating meals out and takeaway meals at home: cross-sectional analysis of the UK national diet and nutrition survey, waves 1-4 (2008-12). Int J Behav Nutr Phys Act. 2015;12(1): 51. https://doi.org/10.1186/s12966-015-0210-8.

36. Rogers I, Emmett P. The effect of maternal smoking status, educational level and age on food and nutrient intakes in preschool children: results from the Avon longitudinal study of parents and children. Eur J Clin Nutr. 2003; 57(7):854-64. https://doi.org/10.1038/s.ejcn.1601619.

37. Dovey TM, Staples PA, Gibson EL, Halford JC. Food neophobia and 'picky/ fussy' eating in children: a review. Appetite. 2008;50(2-3):181-93. https://doi. org/10.1016/j.appet.2007.09.009

38. Lachat C, le NB K, Khan NC, Dung NQ, do VA N, Roberfroid D, et al. Eating out of home in Vietnamese adolescents: socioeconomic factors and dietary associations. Am J Clin Nutr. 2009;90(6):1648-55. https://doi.org/10.3945/a jcn.2009.28371.

39. Zang J, Luo B, Wang Y, Zhu Z, Wang Z, He X, et al. Eating out-of-home in adult residents in shanghai and the nutritional differences among dining places. Nutrients. 2018;10(7):951.

40. Li M, Xue H, Jia P, Zhao Y, Wang Z, Xu F, et al. Pocket money, eating behaviors, and weight status among Chinese children: the childhood obesity study in China mega-cities. Prev Med. 2017;100:208-15. https://doi. org/10.1016/j.ypmed.2017.04.031.

41. Ma J, Cai C, Wang H, Dong B, Song Y, Hu P, et al. Trends in overweight and obesity among Chinese children of 7-18 years old during 1985-2010. Zhong Hua Yu Fang Yi Xue Za Zhi. 2012;46(9):776-80.

42. Wang S, Dong Y, Wang Z, Zou Z, Ma J. Trends in overweight and obesity among Chinese children of 7-18 years old during 1985-2014. Zhong Hua Yu Fang Yi Xue Za Zhi. 2017;51(4):300-5.

43. Du WW, Zhang B, Wang HJ, Wang ZH, Su C, Zhang JG, et al. Gender difference in the association between food away-from-home consumption and body weight outcomes among Chinese adults. Public Health Nutr. 2016:19(16):2984-90. https://doi.org/10.1017/S1368980016001257.

44. Taillie LS, Afeiche MC, Eldridge AL, Popkin BM. The contribution of at-home and away-from-home food to dietary intake among 2-13-year-old Mexican children. Public Health Nutr. 2017;20(14):2559-68. https://doi.org/10.1017/ S1368980016002196.

45. Xu F, Ware RS, Leslie E, Tse LA, Wang Z, Li J, et al. Effectiveness of a randomized controlled lifestyle intervention to prevent obesity among Chinese primary school students: CLICK-obesity study. PLoS One. 2015; 10(10):e0141421. https://doi.org/10.1371/journal.pone.0141421.

46. Lu C, Wang Z, Dong Y, Ma J. Prevalence of weight-loss behaviors and the associations betweenweight-loss behaviors and weight-related perceptions among students in primary and middle schools in China. Chin J School Health. 2017;3:330-3.

47. Mushtaq MU, Gull S, Mushtaq K, Shahid U, Shad MA, Akram J. Dietary behaviors, physical activity and sedentary lifestyle associated with overweight and obesity, and their socio-demographic correlates, among Pakistani primary school children. Int J Behav Nutr Phys Act. 2011;8(1):130. https://doi.org/10.1186/1479-5868-8-130.

48. Matheson DM, Killen JD, Wang Y, Varady A, Robinson TN. Children's food consumption during television viewing. Am J Clin Nutr. 2004;79(6):1088-94. https://doi.org/10.1093/ajcn/79.6.1088.

\section{Publisher's Note}

Springer Nature remains neutral with regard to jurisdictional claims in published maps and institutional affiliations.

Ready to submit your research? Choose BMC and benefit from:

- fast, convenient online submission

- thorough peer review by experienced researchers in your field

- rapid publication on acceptance

- support for research data, including large and complex data types

- gold Open Access which fosters wider collaboration and increased citations

- maximum visibility for your research: over $100 \mathrm{M}$ website views per year

At BMC, research is always in progress.

Learn more biomedcentral.com/submissions 